\title{
The Design of Gis-Based Anti-Seismic And Disaster-Prevention Assistant Analysis System For Lifeline
}

\author{
Xiufen $\mathrm{Li}^{1, \mathrm{a}}$, Fei Wang ${ }^{1, \mathrm{~b}}$ \\ ${ }^{1}$ Hebei GEO University, Shijiazhuang, Hebei, 050031,China \\ a276688718@qq.com, b147152587@qq.com
}

Keywords: GIS; lifeline system; anti-seismic and disaster-prevention; database

Abstract: This paper studies the design of GIS-based anti-seismic and disaster-prevention assistant analysis system for lifeline accordance with GIS developing process. This paper discusses the design process of GIS-based anti-seismic and disaster-prevention assistant analysis system for lifeline, ascertains the design principle of the system, and accordingly puts forward a complete general design thought.

\section{Introduction}

The amount of data needed to analysis the Seismic damage to urban lifeline system is very big, this bring trouble on the earthquake damage assessment; At the same time, the amount of data make it diffi-cult to know exactly the damage of transformer sub-station or road, and even do not know how to start $^{[1],[2]}$. While, the GIS is an information system with powerful functions, it can not only meet the needs of the above, also can provide more function to GIS-Based anti-seismic and disaster-prevention assistant analysis system for lifeline.

\section{The design process of assistant analysis system}

The design process of GIS-based anti-seismic and disaster-prevention assistant analysis system for life-line includes the following procedures:

(1) System Analysis: Through a thorough investi-gation and study to the users of the system, based on the specific aim of anti-seismic and disaster-prevention system for lifeline, analyze and synthe-size the lifeline system. Finally, analyzing the feasi-bility of various schemes, find out the most optimal solution of structure. Tasks in this stage is to inves-tigation and study the system users, conduct in-depth investigation and analysis on the basis defined goals of lifeline earthquake disaster reduction system, finally put forward the structure scheme.

(2) System Design: System designing includes general system designing and detailed system de-signing. The general system design is to answer the question "the system should be how to realize". Its main task is to differentiate the composition of the physical elements, links and its description of defini-tion. And according to the application object of sys-tem, configure the appropriate model and the proper number of appropriate hardware and software, then to determine the computer operating environment. The detailed design mainly includes the software de-sign, code design, functional design, database de-sign, user interface design, design of input and out-put, etc.

(3) System Implementation: The main tasks of this stage include:(1) Hardware preparation: This mainly includes computer, input and output devices, storage devices, auxiliary equipment and communi-cations equipment, etc. (2)Software preparation: This mainly includes the system software, database management system and some applications. (3)Personnel training: This is mainly refers to the train-ing of users. (4)Data Preparation: This is mainly in-cludes Data collection, sorting and entry.

(4) Operation and Maintenance: In the process of using, constantly perfects the system, maintains the programs, data files, code, machine and equipment.

\section{The design of lifeline system}

The system objectives and function requirements: In the past, Earthquake emergency decision making mainly depends on temporary headquarters, Now, with the development of geographic 
information sys-tem, decision makers can make effective decisions, People can carry out predetermined plan and execute manual intervention. Design objectives of the system mainly include the following aspects ${ }^{[3],[4]}$ :

(1) Analyzing seismic damage of lifeline system. Before destruction of earthquake disaster, the gov-ernment departments can draw up anti-earthquake and relief work plan according to the number of life-line engineering, distribution, anti-seismic ability provided by the system; when the earthquake strikes, the system can be quick launched, providing the ba-sis of implementation of destructive disaster contin-gency plans for government. After the earthquake, the assessment of earthquake loss and earthquake-recovery work can be done based on the system.

(2) Assessing seismic safety of lifeline engineer-ing. The system could satisfy the requirements of ur-ban comprehensive disaster reduction, at the same

time, also provide the service for urban planning and construction.

(3) Achieving human-computer interaction. GIS-based anti-seismic and disaster-prevention assistant analysis system for lifeline is a friendly-faced, easy-to-operate and finely designed software.

The above goals have determined functions of lifeline anti-seismic and disaster-prevention assistant analysis system based on GIS. Its main functions are as follows.

(1) Information query. The system inquires about attribute data of urban lifeline engineering and spatial data, also includes some urban basic infor-mation query.

(2) Seismic damage analysis of lifeline engineer-ing. Under the earthquakes action of various intensi-ties, the system can calculate Earthquake damage, display seismic damage degree, count up damage, and generate a variety of thematic map. These pro-vide the basis for the government to manage and as-sist policy decision, and service for urban planning, construction.

(3) To be convenient for users, design a friendly man-machine interface, So as to better play to the function of the system.

Principle of system design : In designing the lifeline anti-seismic and disaster-prevention assistant analysis system based on GIS, adhere to the following principles ${ }^{[5]}$ :

(1) User-oriented principle. System is easy to user operation; provide the necessary information and data for the daily management, earthquake emergency rescue and seismic rehabilitation, for solving the practical problems users. Furthermore, the customer's problems can be solved successfully.

(2) Advance principle. System development is based on a higher level, the use of the current mature technology ensure the performance of the system;

(3) Standardization Principle, normalization Principle. The design of the system needs to be done in accordance with the requirements of the standard-ized design and development of GIS, and should follow the national and local industry technical standards and specifications.

(4) Scalability principle: Hardware and software, coding system, each function module should have the higher expandability, and ensure the compatibil-ity and stability.

(5) Opening principle. System software has inter-face with other systems.

General design of lifeline anti-seismic and disaster-prevention assistant analysis system based on GIS: The general design of system is shown in figure 1.

The integration of lifeline anti-seismic and disaster-prevention assistant analysis system based on GIS: Lifeline anti-seismic and disaster-prevention assis-tant analysis system based on GIS mainly includes the following sections:

(1) The urban fundamental information system

This subsystem consists of administrative division database, town database, streets database, road database, river database, site category database, etc. Its function is to provide all kinds of basic geograph-ical background information, and the combination of a variety of database graphics library, etc. Then we can know the basic information of the city.

(2) The anti-seismic and disaster-prevention as-sistant analysis system of city's lifeline engineering

The subsystem is mainly composed of lifeline earthquake damage analysis database and thematic map (urban power system diagram, traffic system di-agram, water supply system diagram, etc.). 
Database includes power supply, transportation, water supply system database and earthquake damage analysis da-tabase under the action of different intensity earth-quake, etc. Its function is to provide based infor-mation query of the urban lifeline system and analysis of lifeline earthquake damage, and provide lifeline and earthquake information service and the query for the city government management depart-ments, earthquakes and other disasters management department, the department in charge of the lifeline system, insurance companies, urban planning and re-al estate developers, urban public administration.

(3) Information management system

In addition to the above subsystem, basic geo-graphic information and professional information da-tabase of Lifeline anti-seismic and disaster-prevention assistant analysis system based on GIS can freely be stacked and combined according to the needs of different precision, different scale, different purposes and requirements, different professional requirements of rich thematic map, provide vast amounts of information service and dynamic management for urban planning and national economy in all walks of life.

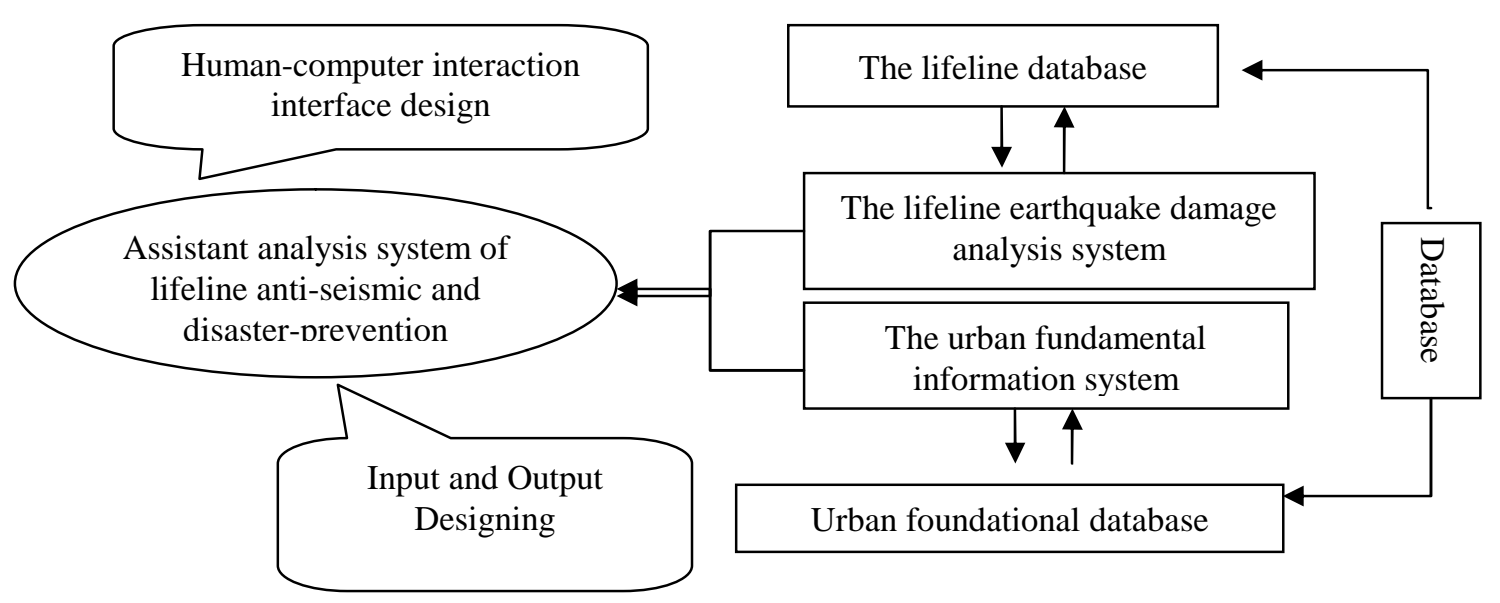

Fig.1 Design flow chart of GIS-based anti-seismic and disaster-prevention analysis system for lifeline

(4) Basic data update and maintenance module

This module in combination with the needs of us-ers, provides the main data maintenance function based on GIS software platform, enables users to maintain system database of seismic disaster preven-tion aided analysis of lifeline. The system data up-date functions include: add and remove fundamental data, modify base map layers and update the data store.

System integration diagram is shown in figure 2.

The design and implementation of GIS human-computer interaction interface:

The choice of development tools : Considering the advantages and disadvantages of GIS professional development tools and $\mathrm{VC}++$ de-velopment tools, this paper adopts the general graphical interface development tools $-\mathrm{VC}++$, during the development process of geographic in-formation system. Using $\mathrm{VC}++$ not only, it can meet the flexibility which needed by the special re-quirements of GIS professional development tools, and you can also increase or improve the corre-sponding function, according to user needs in the fu-ture, Thus ensure product development can meet the user's requirements.

The graphical interface design requirements: When designing a graphical interface, consider the following two requirements:

(1) Interface layout.

(1)The graphical interface include menu, graphics, data display and graphic control area and other parts, and the graphics display area accounts for a large ar-ea as far as possible. (2)To establish a convenient tool bar. (3) To realize the direct control of the graphic display, including local amplification, step-less zoom, panoramic map display and roaming, etc. 
(2) Interactive performance requirements.

(1) Realizing real-time performance of human-computer interaction, the system need update the graphics area timely; show the user operation results timely, that is to say the feedback information is submitted in time. (2) In the interaction with the sys-tem, the operator will inevitably make mistakes, therefore, the system design should fully consider the requirements of system robustness; (3)When cer-tain actions have irreversible negative consequences, the system should be predict destructive operation to users, and require the user to confirm or save the file in advance.

Proving Graphics functions: The graphical functions of Power supply system, transportation system, and water supply system in-clude general graphical capabilities and professional graphics functions. These function module need to complete the following tasks: data input, data modi-fy, and data delete; data query; the analysis of seis-mic damage and the statistics of damage. The statis-tical result is displayed in the graphics window.

Input and Output Designing: The graphic input methods of lifeline anti-seismic and disaster-prevention assistant analysis system based on GIS include Keyboard inputting point co-ordinate mapping, Scanning digitizing mapping, Digital mapping, coordinate information automatic mapping by read the graphics, point, line that have been stored in the file, and convertformat to map.

The graphic output design of lifeline anti-seismic and disaster-prevention assistant analysis system based on GIS includes Graphical output design and the Form output design. Graphical output is mainly output the system analysis and data processing re-sults to the user in the way of maps, graphs, statisti-cal figure maps. Graphical output design is mainly to choose symbols, locate symbols, choose linear, select color and note configuration. Form output design goal is to make the output form to clear, beautiful, easy to read and understand.

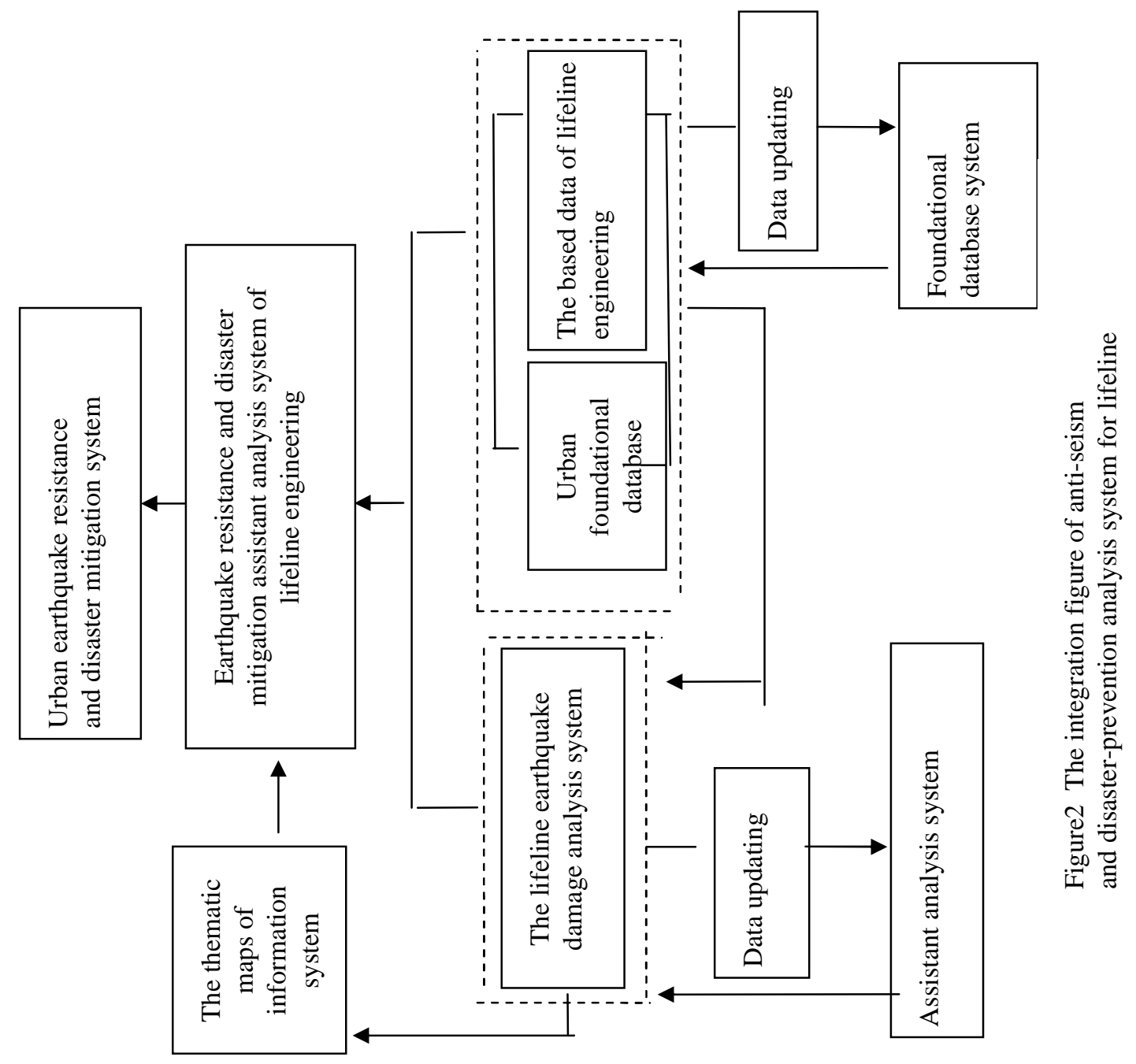




\section{Conclusion}

This paper studies the design of lifeline anti-seismic and disaster-prevention assistant analysis system based on GIS. Through the establishment of Earth-quake resistance and disaster mitigation assistant analysis system of lifeline engineering, seismic dam-age of the lifeline can be predicted, and to meet the needs of urban comprehensive disaster prevention, provide service for urban planning and construction.

\section{References}

[1] Youpo su, Jingyu su, Chunsheng Su etc. Basic theory and practice of urban lifeline system about the earthquake recovery [M]. The earthquake pub-lishing house.2002:1 3 (In Chinese)

[2] Chenggang zhao. Several basic problems of life-line earthquake engineering[J]. Earthquake Engi-neering and Engineering Vibration, 1993(13)

[3]Stephanic E. Chang, Hope A. Seligson, Ronald T. Eguchi. Estimation of Economics Losses Caused by Disruption of Lifeline Service: An Analysis of the Memphis Light, Gas and Water System, Lifeline earthquake engineerinig[D]. Technical Council on Lifeline Earthquake Engineering, Monograph No, 4 August, 1991:48 55

[4] Leon Wang R-L,Yeh Y H. Refined seismic anal-ysis and design of buried pipeline for fault move-ment[J]. EESD, 1985,13:75 96

[5] Duke C M. An earthquake hazard plan for life-lines. ASCE. Life earthquake engineering. 